\title{
Two Different Epistemologies about Limit Concepts
}

\author{
Dong-Joong Kim ${ }^{1}$, Hyangim Kang ${ }^{2} \&$ Hyun-Joo Lee ${ }^{3}$ \\ ${ }^{1}$ Department of Mathematics Education, Korea University, Seoul, South Korea \\ ${ }^{2}$ Department of Mathematics Education, Korea National University of Education, Chungbuk, South Korea \\ ${ }^{3}$ Daejeon Dongsin Science High School, Daejeon, South Korea \\ Correspondence: Dong-Joong Kim, Department of Mathematics Education, Korea University, Seoul 136-701, \\ South Korea. Tel: 82-2-3290-2331. E-mail: dongjoongkim@korea.ac.kr
}

\author{
Received: October 22, 2014 Accepted: November 20, 2014 Online Published: February 25, 2015 \\ doi:10.5539/ies.v8n3p138 URL: http://dx.doi.org/10.5539/ies.v8n3p138
}

\begin{abstract}
The purpose of this study is to investigate characteristics of limit concepts through the simultaneous use of historical and experimental epistemologies. Based on a historical epistemology which is an investigation of historical developments in a mathematical concept raised in the history of mathematics, four different developments of limit concepts were considered. Through an experimental epistemology which is an analysis of students' different stages in the development of their understanding of the mathematical concept, diverse developmental levels were scrutinized to find out how the students performed. Nine pairs of students in total were recruited and three representatives were presented. Results indicate that both historical and experimental epistemologies are useful methods for teaching mathematics along with the unpacking process and that experimental epistemologies are effective because mathematics learning is continuous.
\end{abstract}

Keywords: limit, historical epistemologies, experimental epistemologies

\section{Introduction}

Since the nineteenth century, the concept of limit has been foundational to how calculus and mathematical analysis deal with other notions such as continuity, differentiability, and integration. It is also an important concept that is applicable to the concepts of number line and infinite decimal with the concept of infinity. In the middle school curriculum in Korea, the concept of the infinite involves finite and infinite sets, the area of a sector and the length of an arc, the recurring and nonrepeating decimals, and irrational numbers (Park, Kim et al., 2010; Park, Nam et al., 2010; Park, Yeo et al., 2010). In the high school curriculum, the concept of infinity is expanded to include differential and integral calculus, the limit definition of a series, the convergence and divergence of infinite series, and the limit and continuity of functions (Hwang et al., 2010; Lee et al., 2010; Lew et al., 2010a, 2010b). However, as evidenced by many research results, most students have considerable difficulties with the notions of infinity and limit (Cottrill et al., 1996; Jahnke, 2001; Kang, 2008; Mamona-Downs, 2001; Przenioslo, 2004; Tall, 1992; Weller et al., 2004; Williams, 2001).

The purpose of this study is to investigate how to structuralize limit concepts with an understanding of historical epistemology and to make the structural construction more accessible to students through the unpacking processes of teaching the concepts by using experimental epistemologies. In this study, a historical epistemology is a structural analysis of the developmental stages of a mathematical concept in the history of mathematics, whereas an experimental epistemology refers to an examination of different developmental levels of students in learning the concept.

The first basic assumption in this study is derived from the fact that students' understanding is a continuous variable in their learning process (Sierpinska, 1996). The second important assumption is that students' learning process involves thinking with and through their experimental epistemologies, generalizing the experimental epistemologies with either a lower historical epistemology or a lower curriculum epistemology, and incorporating these epistemologies with what they are taught. Thus, one approach to students' learning difficulties is to analyze their experimental epistemologies in order to fill in the gap between two different historical or curricular epistemologies in a continuous understanding process. For instance, how should we teach $0 . \dot{9}=0.999 \cdots=1$ in class? In the current curriculum, students are usually taught by the intrusive way of using the formal definition which has been developed over the history of mathematics. However, we can build on the 
concept of informal-negation (i.e., there is no number between a limit and its process) to teach the concept of $0.999 \cdots=1$. Applying this concept of informal-negation may help students overcome their learning difficulties in continuous understanding processes because this kind of students' experimental epistemologies can fill in the disparity between students' intuition and the formal and rigorous definition.

Therefore, in this study, a structural analysis of limit concepts was explored on the basis of four different historical epistemologies. In addition to the structural analysis, four experimental epistemologies at different levels were investigated for unpacking processes of understanding these concepts. Thus, this study attempts to answer the questions raised by learning difficulties by showing the role of both experimental and historical epistemologies in the continuous process of learning and teaching limit concepts.

\section{Theoretical Background}

\subsection{Nature of Learning Mathematics}

In absolutism, mathematics is absolute truths and thus is viewed as a collection of both complete concepts and their operational principles. In contrast, the mathematics that human beings know is a humanmind-based mathematics in relativism (Hersh, 1997). In addition, mathematics can be seen as a product of the human mind and our social and cultural history in a socio-cultural perspective. From the socio-cultural perspective, relativism as a view on the nature of mathematics is a noticeable feature. In this study, we formulated learning mathematics as a cognitive, social and cultural process. Thus, not only intra-personal discourse but also inter-personal discourse is of principle importance in learning mathematics as an activity. Through this lens, we analyzed not only historical developments but also socio-cultural developments, particularly when examining developmental trajectories of students. For the study, inherently historical developments are the focus of investigating in examining intra-personal discourse, whereas socio-cultural developments are perceived mainly as inter-personal discourse in a pair.

\subsection{Historical Epistemology}

In the history of mathematics, the mathematical concepts of infinity and limit have been developed through four different epistemological developments: intuitive finitism, infinitism in the context of infinitesimals, infinitism in the context of variables, and actual infinitism (Kim, 2010). Intuitive finitism was developed by ancient Greek philosophers (Moore, 1990). This epistemology can be called as intuitive finitism because it is based on geometrical intuition and excludes infinite processes. Although there was the notion of bounded processes in this concept, there was no idea of limit as a concrete bounding entity. Second, infinitism in the context of infinitesimals was formulated in the seventeenth and eighteenth centuries and involved the notion of the potentially infinite. This epistemology concentrated pragmatically on the development of infinitesimal calculus. Although the concept of limits was involved in infinitesimal calculus, it had not been clarified. In Cauchy and Weierstrass' infinitism in the context of variables, the notion of limit emerged as an underlying concept needed to remedy uncertainties and make infinitesimal calculus more rigorous. Infinity was also the potential infinite, and the concept of limit became the fundamental concept of calculus based on the $\varepsilon$ and $\delta$ variables. Limits, in this epistemology, became an arithmetical concept rather than a geometrical concept (as it had been in infinitism in the context of infinitesimals). The concept of the limit based on variables became the rigorous underlying concept of calculus in the former epistemology, while uncertainties and inconsistencies of infinitesimals were the basis of infinitesimal calculus in the latter epistemology. Finally, in the epistemology of actual infinitism demonstrated best by Cantor and Dedekind, infinity was the actual infinite rather than a potential construct, unlike the three previous epistemologies. Limit was also the fundamental concept of calculus. In the view of Cauchy and Weierstrass, an infinitesimal was a variable whose limit is zero and the limit concept involved only the definition of number (Boyer, 1949).

\subsection{Experimental Epistemology}

A (historically) structural analysis of mathematical concepts helps mathematics educators to understand student learning difficulties. For instance, Cottrill et al. (1996) report that there are two reasons for student difficulties with limits. One reason is the need to mentally coordinate two processes: $x \rightarrow a$, and $f(x) \rightarrow L$. The other is the need for a good understanding of quantification related to $\varepsilon$ and $\delta$. As Ball and Bass (2000) pointed out, unpacking the processes of a difficult mathematical concept make it more accessible to students by decompressing its necessary components which are going to be foundational for the study of more advanced mathematics. This is the cognitive root which Tall (1992) advocated.

However, in order to decompress limit concepts, not only the above historical epistemologies, but also experimental epistemologies are needed to develop a better structural analysis because understanding is a 
continuous variable and experimental epistemologies affect student learning in mathematics (see Davis, 2001; Duffin \& Simpson, 2000; Moss \& Case, 1999; Pirie \& Kieren, 1992). In other words, experimental epistemologies are needed for a better understanding of how to structuralize and decompress mathematical concepts to teach mathematics students with diverse levels of knowledge by considering what they already know. Thus, a structural analysis of mathematical concepts should be developed through the simultaneous use of historical and experimental analyses. To develop an in-depth analysis of experimental epistemologies, we analyzed interview data through discourse analysis.

\section{Research Design}

Nine pairs of students participated in this study. All participants completed the given task in a pair to help them express their thinking processes with a guideline. After collecting the transcribed data, experimental epistemologies of all students were compared and contrasted. Nine pairs of students were recruited from three different groups of students in terms of different developmental levels. One representative in each group and thus three representatives in total were presented through discourse analyses on the basis of their experimental epistemologies. Finally, different developmental stages of experimental epistemologies were structuralized to make conjecture about the difference from those of historical epistemologies.

\subsection{Research Questions}

In order to explore the role of unpacking the processes of experimental epistemologies in the structural analysis of historical epistemologies, the following research question was proposed: What are the developmental stages of experimental epistemologies which are different from those of historical epistemologies?

\subsection{Participants}

Nine pairs of students in total were recruited from several elementary and high schools in the middle of South Korea in order to explore experimental epistemologies in depth. Their discourses were analyzed. Of the nine pairs, we presented only three pairs by qualitative methods because these pairs are representative of the others. In order to investigate different experimental epistemologies of limit concepts, three different levels of students were categorized: students who had not learned the concepts, students who had learned the concepts but were possibly not proficient in them, and students who learned the concepts and were potentially good at them. In other words, two students from each of the three different groups are described here: two 5 th graders $(5 \mathrm{~A}$ and 5B), two 10th graders in a technical/professional high school (10A and 10B), and two 10th graders in a regular high school (10C and 10D).

\subsection{Research Task}

In order to investigate students' experimental epistemologies about limit concepts, the below problem was used. The context and expression of the problem were considered to make it accessible to both 5th graders and 10th graders. In order to minimize 5th graders' difficulty in understanding the problem, three elementary school teachers reviewed it from the perspectives of elementary school students. The below task was designed to investigate students' different experimental epistemologies as they exhibited their different levels of understanding in a mechanism of solving the same problem.

Problem: The area of the first rectangle is $100 \mathrm{~cm}^{2}$. The area of the second rectangle is reduced to $50 \%$ of that of the first one. The area of the third rectangle is reduced to $50 \%$ of that of the second one: (a) What is the area of the fifth rectangle if you continue this process? (b) What happens to the area if you continue endlessly? (c) Explain how you get your answer in (b).

\subsection{Data Collection}

The interview was used with pairs of students because it may further reveal experimental epistemologies of student thinking. Interviewers assisted each pair of students to clarify his or her thoughts for details whenever the listener was not sure of how the students were thinking (Whimbey \& Lochhead, 1984). In order to minimize the effect of three interviewers on students' ways of thinking during interview, the interviewers used the following prompt. First, while solving these problems, please talk with each other so that I can understand why you think like that. Second, if you cannot understand your partner's problem-solving process, please ask either details or questions. Third, please help each other in order to solve these problems together. Fourth, please think aloud so I can understand your thinking and problem solving process.

\subsection{Data Analysis}

The transcribed data from the paired interviews were used as a primary source to analyze students' experimental epistemologies. The data were analyzed to identify and describe students' experimental epistemologies which 
were different from the four historical epistemologies. These experimental epistemologies were scrutinized by analyzing students' discourse on the same limit problem. At the next stage, several comparisons were made: (a) we looked for similarities and differences between students' experimental epistemologies and the four historical epistemologies; (b) we searched for the place where the experimental epistemologies could be located within and across the four historical epistemologies.

\section{Results}

Through the data analysis, the following four different experimental epistemologies were found: discreteintuitive finitism, continuous intuitive finitism, infinitism in the context of infinitesimals through intuition, infinitism in the context of infinitesimals through examples.

\subsection{Discrete Intuitive Finitism}

The exchange of the two 5th graders was as follows.

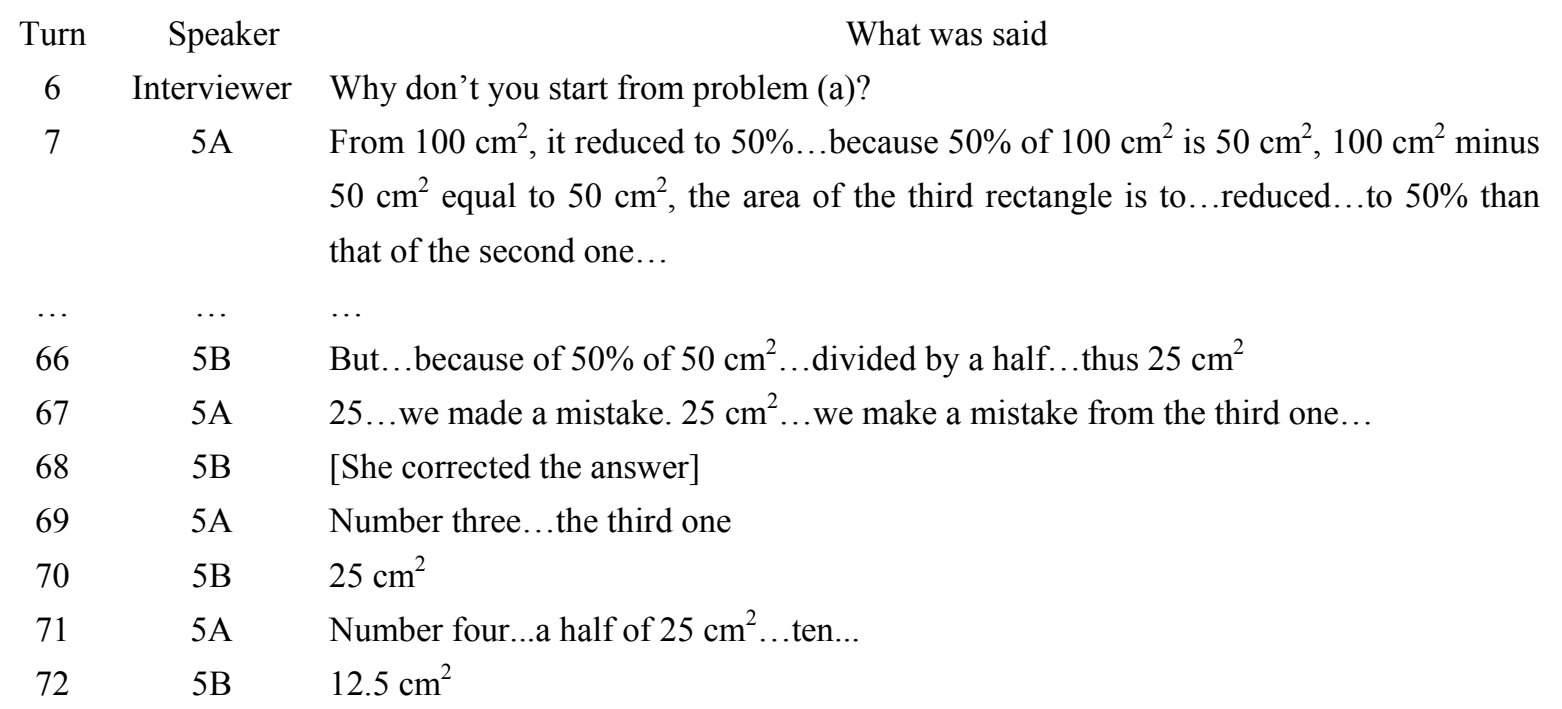

In solving problem (c), the two $5^{\text {th }}$ graders exhibit the epistemology of intuitive finitism because they answered that the area of rectangles "decreases endlessly" without using the limit concept. In addition to the intuitive finitism, they found the area of the fifth rectangle by investigating each area discretely (see 7, 66, and 72 in the turn column). Therefore, the $5^{\text {th }}$ graders' epistemology is discrete intuitive finitism.

\subsection{Continuous Intuitive Finitism}

A dialogue went on between two $10^{\text {th }}$ graders in a technical/professional high school in the form of an exchange of the following sentences.

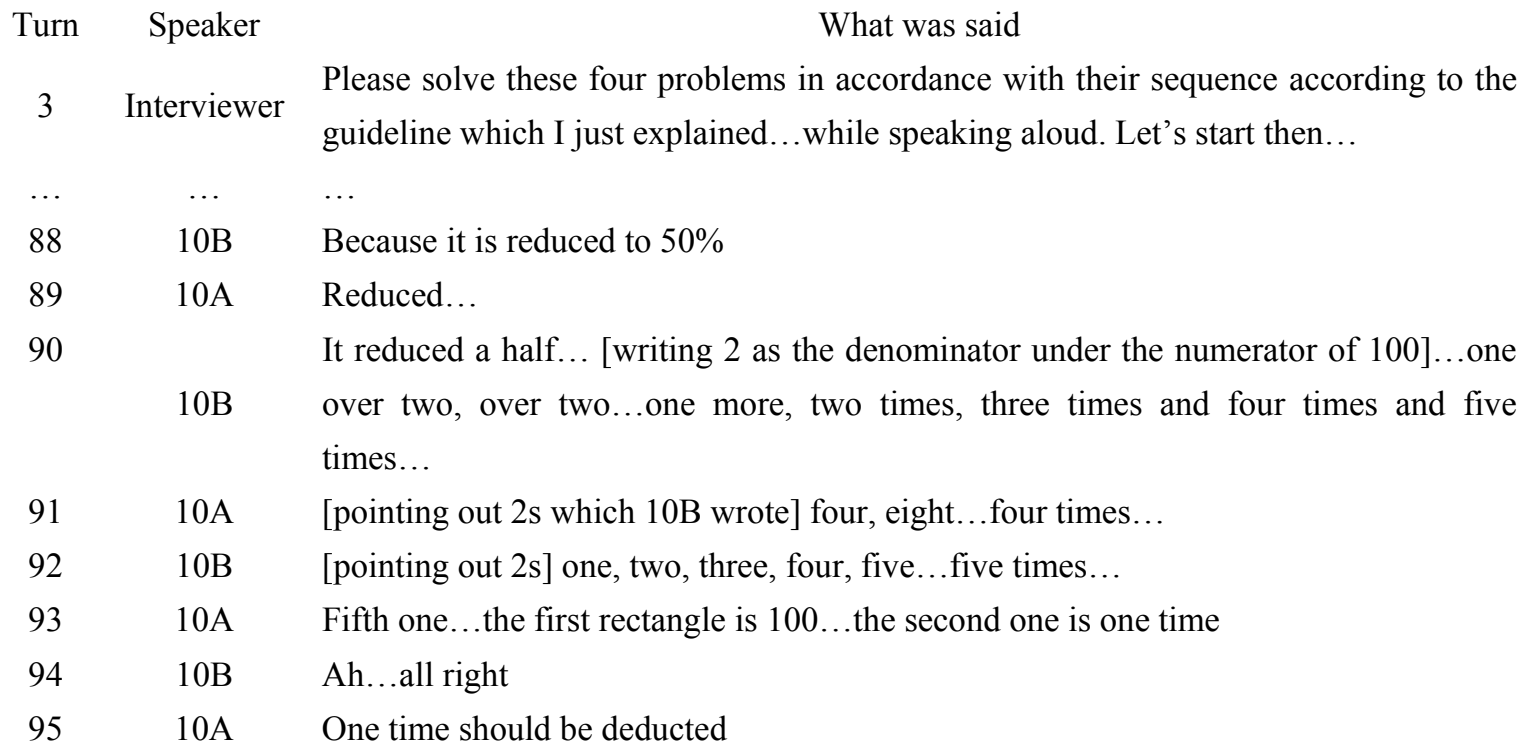


$96 \quad 10 \mathrm{~B} \quad$ Ah...sorry

$97 \quad 10 \mathrm{~A} \quad$ Over sixteen...100 over sixteen.

The transcribed data of two $10^{\text {th }}$ graders in a technical/professional high school show intuitive finitism because they also used the expression of "continue to reduce" to answer problem (b) without employing the limit concept. However, in order to find the area of the fifth rectangle, they made each process of finding it continuous by considering 1/2,1/4,1/8, and 1/16 (see turns 90 and 97). Thus this epistemology can be called continuous intuitive finitism, compared to the $5^{\text {th }}$ graders' discrete intuitive finitism.

\subsection{Infinitism in the Context of Infinitesimals Through Intuition}

Two $10^{\text {th }}$ graders in a regular high school had the following dialogue.

\begin{tabular}{|c|c|c|}
\hline Turn & Speaker & What was said \\
\hline 8 & Interviewer & Why don't you share your idea? \\
\hline$\cdots$ & $\ldots$ & - \\
\hline 11 & $10 \mathrm{D}$ & $\begin{array}{l}\text { Thus this one is reduced to } 50 \% \text {, the second one is reduced to } 50 \% \text {, the third one is } \\
\left.\text { reduced to } 50 \% \text { too [writing } 100 / 2,100 / 2^{2}, 100 / 2^{3}, 100 / 2^{4}\right] \ldots \text { two two...two } \\
\text { three...two four...it is reduced like this...thus it becomes } 25 \text { over } 8 \mathrm{~cm}^{2} \ldots\end{array}$ \\
\hline 12 & $10 \mathrm{C}$ & $\mathrm{Um} \ldots$ \\
\hline 13 & $10 \mathrm{D}$ & $\begin{array}{l}\text {...(c) is....because denominators continue to increase...numerator is constant...this } \\
\text { continues to increase....is it almost diverse to infinity? Because it continues to } \\
\text { increase, } 100 \text { over infinity [writing } 100 / \infty \text { ]...because the denominator is very big and } \\
\text { the numerator is small...it approaches to zero. }\end{array}$ \\
\hline 14 & $10 \mathrm{C}$ & $\mathrm{Um} \ldots$ \\
\hline 15 & $10 \mathrm{D}$ & Thus the area becomes zero... rectangle like this... what about you? \\
\hline 16 & $10 \mathrm{C}$ & $\begin{array}{l}\text { Like you, in problem (a) it continues to decrease to a half... because it's decreasing by } \\
2 \ldots \text { it's division by } 2 \ldots\end{array}$ \\
\hline 17 & 10D & $\mathrm{Um} \ldots$ \\
\hline 18 & $10 \mathrm{C}$ & $\begin{array}{l}\text { I thought like you...in problem (b), even if it continues to decrease to zero, it does } \\
\text { not seem to become zero. I don't think it become zero... }\end{array}$ \\
\hline
\end{tabular}

In problem (c), both $10^{\text {th }}$ graders in a regular high school had the epistemology of infinitism in the context of infinitesimal because they accepted the fact that the area approaches zero. However, even though $10 \mathrm{C}$ had the epistemology of infinitism in the context of infinitesimal, the expression of "even if it continues to decrease to zero, it does not seem to become zero (see turn 18)" shows that his epistemology is based on intuition without providing justification. Therefore, his epistemology can be called infinitism in the context of infinitesimals through intuition.

\subsection{Infinitism in the Context of Infinitesimals through Examples}

In contrast, 10D advocated the expression of "the area becomes zero" (see turn 15). In addition, he explained the reason by using the example of " 0.9999 ...if there are infinitely many 9 , it becomes 1 " (see turn 26 ) and justified his reasoning. Thus this epistemology can be differentiated from the previous epistemology and it can be called infinitism in the context of infinitesimals through examples. However, his reasoning is not completely infinitism in the context of infinitesimals because he admitted that "even if there is one at the end" (see turn 26).

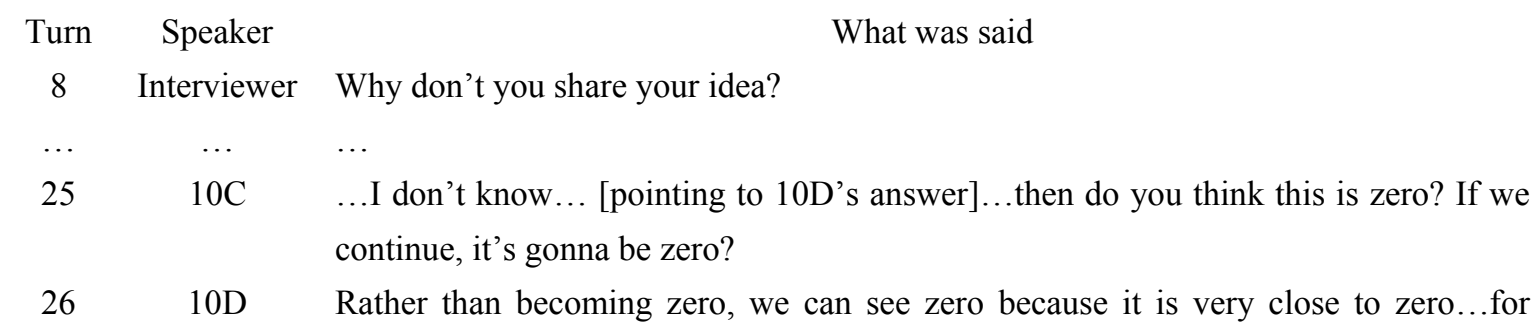


instance, $0.9999 \ldots$ if there are infinitely many 9 , it becomes $1 \ldots$ like this...0.000...if 0 is gonna repeat infinitely many...even if there is one at the end...we can see this as zero...I do think like this.

$27 \quad 10 \mathrm{C} \quad \mathrm{Um} . . .[$ nodding]...I may agree with you...

\section{Discussion}

In this study, we analyzed a mathematical structure of limit concepts on the basis of four historical epistemologies. In addition to the four historical and original epistemologies, we scrutinized four experimental and novel epistemologies that arose from students' different developmental levels. In summary, historically the limit concept has been developed through four different epistemologies: intuitive finitism, infinitism in the context of infinitesimals, infinitism in the context of variables, and actual infinitism. Based on experimental epistemologies of six students, we observed that intuitive finitism included discrete intuitive finitism and continuous intuitive finitism, whereas infinitism in the context of infinitesimals could be developed through two different stages with intuition and examples. As shown in Table 1, we can see four experimental epistemologies that are different from four historical epistemologies.

Although the sample size of the current study is too small to allow for generalization, what we found in this study may provide insight into the role of experimental epistemologies in mathematical thinking. On the grounds of our findings, first, we propose that students' experimental epistemologies of mathematical concepts should be analyzed in terms of continuous learning processes through discourse analysis in order to have a better understanding of the development stages and the difficulties in learning. Students' experimental epistemologies may not only include diverse levels of development but also differ from historical development or the prescribed or currently accepted ways of learning and doing. Thus, analyzing students' experimental epistemologies as foundational concepts of what they already know in the continuous process of learning mathematics may be the first priority to understand their developmental stages and a necessary component to develop thinking mechanisms by which they can apply their "primitive knowing" (Pirie \& Kieren, 1992) to historical or curricular structure.

Second, not only students' current experimental epistemologies of mathematical concepts, but also developmentally structural analyses of these concepts (e.g., Cottrill et al., 1996) are important to understand if teachers want to better understand how to handle students' learning difficulties. These structural analyses, however, can become more meaningful with the help of students' experimental epistemological analyses related to the structural analyses. Further, the effect of experimental epistemology on structural analysis may resolve a misalignment between learning and teaching and even close the gap between theory and practice.

Finally, in order to help student learning difficulties, not only historical epistemologies but also experimental epistemologies must play an important role in developing a new epistemology for unpacking the processes of learning and teaching mathematical concepts. For instance, we observed discrete intuitive finitism and continuous intuitive finitism as aspects of intuitive finitism. Obviously, we can develop at least two different stages in intuitive finitism, because an understanding of discrete intuitive finitism develops before an understanding of continuous intuitive finitism in continuous learning processes. Similarly, combining the historical and experimental epistemologies, teachers can plan their lessons with well-structured unpacked stages and handle students' dynamically different experimental epistemologies which are not currently accounted for in historical or curricular developments. This new approach to teaching mathematics may help students deal with their learning difficulties. 
Table 1. Historical and experimental epistemologies

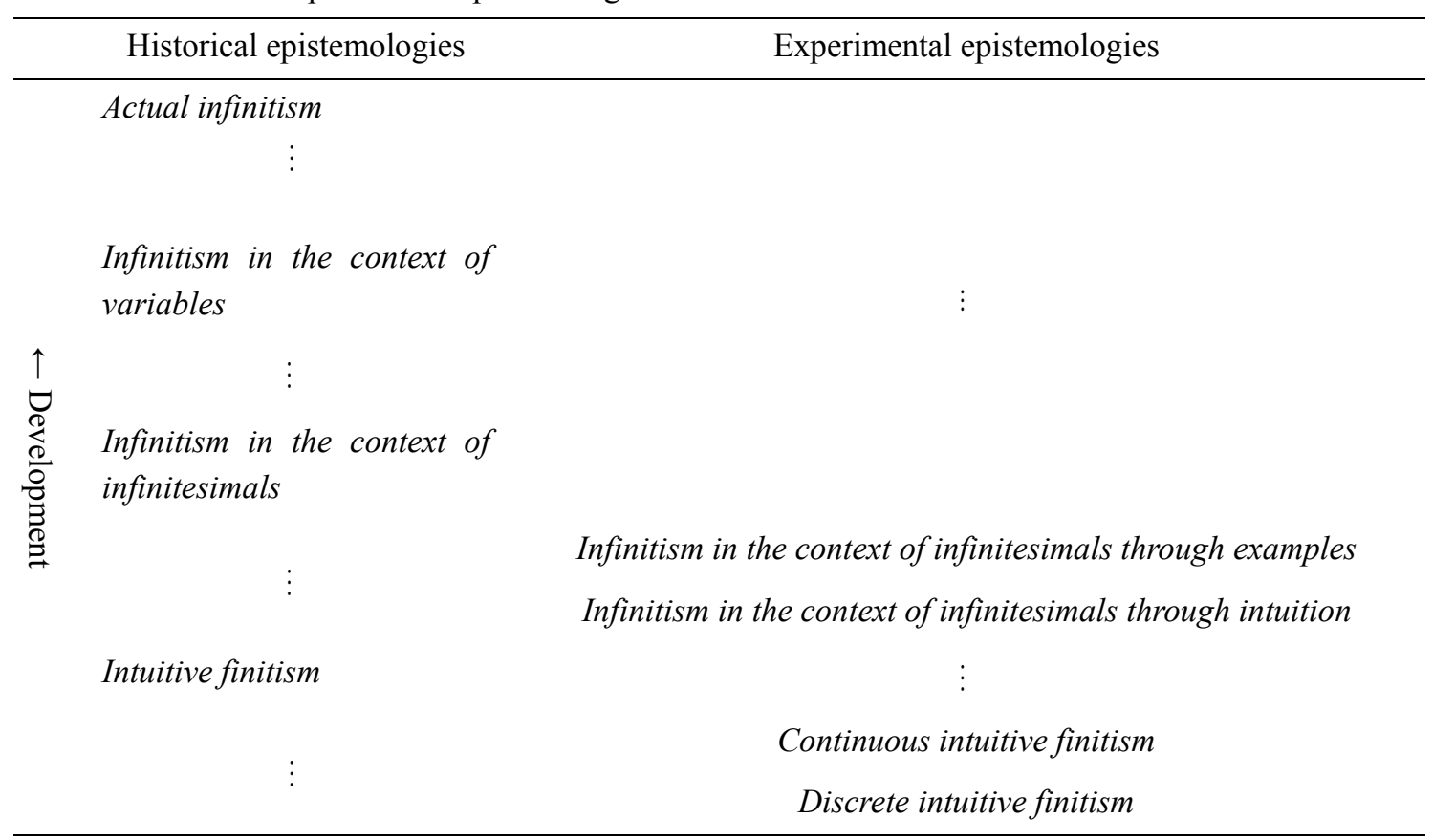

\section{Acknowledgements}

This research was supported by the College of Education, Korea University Grant in 2014. We would like to thank Sang-Hoon Shin for his help in data collection for this research.

\section{References}

Ball, D. L., \& Bass, H. (2000). Interweaving content and pedagogy in teaching and learning to teach: Knowing and using mathematics. In J. Boaler (Ed.), Multiple perspectives on the teaching and learning of mathematics (pp. 83-104). Westport, CT: Ablex.

Boyer, C. (1949). The history of the calculus and its conceptual development. New York, NY: Dover.

Cottrill, J., Dubinsky, E., Nichols, D., Schwingendorf, K., Thomas, K., \& Vidakovic, D. (1996). Understanding the limit concept: Beginning with a coordinated process scheme. Journal of Mathematical Behavior, 15, 167-192. http://dx.doi.org/10.1016/S0732-3123(96)90015-2

Davis, A. (2001). Teaching for understanding in primary mathematics. Evaluation \& Research in Education, 15(3), 136-142. http://dx.doi.org/10.1080/09500790108666991

Duffin, J. M., \& Simpson, A. P. (2000). A search for understanding. Journal of Mathematical Behavior, 18(4), 415-427. http://dx.doi.org/10.1016/S0732-3123(00)00028-6

Hersh, R. (1997). What is mathematics, really? New York, NY: Oxford University Press.

Hwang, S., Im, S., Kim, I., Kang, S., Kim, G., Kim, J., . . Choi, J. (2010). Calculus and Basic Statistics. Seoul, Korea: Kyohak Publishing Co. Ltd.

Jahnke, H. N. (2001). Cantor's cardinal and ordinal infinites: An epistemological and didactic view. Educational Studies in Mathematics, 48, 175-197. http://dx.doi.org/10.1023/A:1016052726876

Kang, M. K. (2008). A Study on the instruction of Infinity Concept with suitable examples-focused on Curriculum of Middle School. Ser. A: The Mathematical Education, 47(4), 447-465.

Kim, D. (2010). The histories of the mathematical concepts of infinity and limit in a three-fold role. The Journal of Educational Research in Mathematics, 20(3), 293-303.

Lee, J., Choi, B., Kim, D., Seo, J., Jeon, Y., Kim, H., . . Song, J. (2010). Mathematics II. Seoul, Korea: Chunjae Educ. Publications.

Lew, H. C., Jo, Y., Son, H., Jo, J., Lee, B., Kim, Y., . . Jeong, S. (2010a). Mathematics I. Seoul, Korea: Mirae N Culture Group Co. Ltd. 
Lew, H. C., Jo, Y., Son, H., Jo, J., Lee, B., Kim, Y., . . Jeong, S. (2010b). Integral and Statistics. Seoul, Korea: Mirae N Culture Group Co. Ltd.

Mamona-Downs, J. (2001). Letting the intuitive bear on the formal: A didactical approach for the understanding of the limit of a sequence. Educational Studies in Mathematics, 48, 259-288. http://dx.doi.org/10.1023/A:1016004822476

Moore, A. W. (1990). The Infinite. London: Routledge. http://dx.doi.org/10.4324/9780203415887

Moss, J., \& Case, R. (1999). Developing children's understanding of the rational numbers: A new model and experimental curriculum. Journal for Research in Mathematics Education, 30(2), 122-147. http://dx.doi.org/10.2307/749607

Park, K. H., Kim, B., Ahn, S., Kim, J., \& Yu, M. (2010). Middle School Mathematics 2. Seoul, Korea: Donghwa Publishing Co. Ltd.

Park, Y. B., Nam, S. Choi, S., \& Hong, Y. (2010). Middle School Mathematics 2. Seoul, Korea: Woongjin Thinkbig Co. Ltd.

Park, Y. H., Yeo, T., Kim, S., Sim, S., Lee, T., \& Kim, S. (2010). Middle School Mathematics 2. Seoul, Korea: Chunjae Moonhwa Co. Ltd.

Pirie, S. E. B., \& Kieren, T. E. (1992). Watching Sandy's understanding grow. Journal of Mathematical Behavior, $11,243-257$.

Przenioslo, M. (2004). Image of the limit of function formed in the course of mathematical studies at the $\begin{array}{llll}\text { university. } \quad \text { Educational } & \text { Studies in }\end{array}$ http://dx.doi.org/10.1023/B:EDUC.0000017667.70982.05

Sierpinska, A. (1996). Understanding in mathematics. London: Routledge.

Tall, D. (1992). The transition to advanced mathematical thinking: Functions, limits, infinity and proof. In D. A. Grouws (Ed.), Handbook of research on mathematics teaching and learning (pp. 495-511). New York: Macmillan.

Weller, K., Brown, A., Dubinsky, E., McDonald, M., \& Stenger, C. (2004). Intimations of infinity. Notices of the American Mathematical Society, 51, 741-750.

Whimbey, A., \& Lochhead, J. (1982). Beyond problem solving and comprehension: An exploration of quantitative reasoning. Hillsdale, New Jersey: Lawrence Erlbaum Associates.

Williams, S. R. (2001). Predications of the limit concept: An application of repertory grids. Journal for Research in Mathematics Education, 32(4), 343-367. http://dx.doi.org/10.2307/749699

\section{Copyrights}

Copyright for this article is retained by the author(s), with first publication rights granted to the journal.

This is an open-access article distributed under the terms and conditions of the Creative Commons Attribution license (http://creativecommons.org/licenses/by/3.0/). 